Disclosure of Interests: Geoffrey Gillard Shareholder of: Magenta Therapeutics, Employee of: Magenta Therapeutics, Jennifer Proctor Shareholder of: Magenta Therapeutics, Employee of: Magenta Therapeutics, Sharon Hyzy Shareholder of: Magenta Therapeutics, Employee of: Magenta Therapeutics, Oliver Mikse Shareholder of: Magenta Therapeutics, Employee of: Magenta Therapeutics, Tahirih Lamothe Shareholder of: Magenta Therapeutics, Employee of: Magenta Therapeutics, Sean McDonough Shareholder of: Magenta Therapeutics, Employee of: Magenta Therapeutics, Nicholas Clark Shareholder of: Magenta Therapeutics, Employee of: Magenta Therapeutics, Rahul Palchaudhuri Shareholder of: Magenta Therapeutics, Employee of: Magenta Therapeutics, Anjali Bhat Shareholder of: Magenta Therapeutics, Employee of: Magenta Therapeutics, Melissa Brooks Shareholder of: Magenta Therapeutics, Employee of: Magenta Therapeutics, Ganapathy Sarma Shareholder of: Magenta Therapeutics, Employee of: Magenta Therapeutics, Prashant Bhattarai Shareholder of: Magenta Therapeutics, Employee of: Magenta Therapeutics, Pranoti Sawant Shareholder of: Magenta Therapeutics, Employee of: Magenta Therapeutics, Brad Pearse Shareholder of: Magenta Therapeutics, Employee of: Magenta Therapeutics, Charlotte McDonagh Shareholder of: Magenta Therapeutics, Employee of: Magenta Therapeutics, Tony Boitano Shareholder of: Magenta, Employee of: Magenta, Michael Cooke Shareholder of: Magenta, Employee of: Magenta

DOI: 10.1136/annrheumdis-2020-eular.5744

\section{OP0308-PARE PREGNANCY AND ARTHRITIS - A PATIENT EDUCATION PROGRAMME IN IRELAND}

\section{B. Lynch ${ }^{1} .{ }^{1}$ Arthritis Ireland, Dublin, Ireland}

Background: The relationship between pregnancy and arthritis is a complex one. Because of the variability of arthritic conditions, it is important for patients to get advice from their doctor or a specialist nurse before trying for a baby. There can be implications for medication regimes, while the pregnancy itself can also affect the inflammatory arthritis. In the postpartum period, other considerations include breastfeeding and the frequent return of flares.

Through this education programme, Arthritis Ireland developed information resources primarily targeting women of child-bearing age. The multichannel campaign provided information about the wide range of issues of concern to women with inflammatory arthritis who are planning a family or are pregnant. Objectives:

- To provide information and increase awareness around inflammatory arthritis and pregnancy;

- To support women living with inflammatory arthritis through their illness and life journey;

- To increase awareness of the work of Arthritis Ireland as a patient organisation. Methods: In developing and executing this education programme, Arthritis Ireland worked extensively with a team of healthcare professionals, who are regarded internationally as leaders in this field.

A multi-channel approach was taken to the development, production and dissemination of information, with public information events, literature and a suite of videos developed

Up to this point, there had not been any Irish-produced material on this subject. he topic was seen to be an important one and an issue of significant public health interest.

The series of information talks on pregnancy and inflammatory arthritis was delivered by consultant rheumatologists and were held in cities around Ireland. The information booklet covered topics such as planning for a baby, medication and pregnancy, the role of the father, fertility, genetics, during the pregnancy, after the pregnancy and breastfeeding.

Video was seen to be central to the success of the campaign. Working with the expert healthcare team, six information videos were developed around obstetrics, rheumatology, physiotherapy and occupational therapy. The videos were published and promoted across Arthritis Ireland's social media channels and website.

The capstone video featured a young mother who was diagnosed with JIA when she was two. Her story was an incredibly powerful testimony of overcoming and dealing with adversity and complex health issues.

Results: This educational campaign was developed to meet a significant need in the health information landscape. While there are no little resources produced focusing on pregnancy and parenting, there wasn't anything in Ireland which specifically addressed the needs of women and men with inflammatory arthritis who are looking to have a family. The materials produced are a valuable part of Arthritis Ireland's canon of patient education materials.

Conclusion: It is anticipated that the materials developed will have a long lifespan and will support prospective parents for several years to come. Central to the success of the project was the involvement of the expert healthcare teams. Their commitment to the project spoke volumes of its importance and the considerable need for the clearly communicated information, which the project provided.
Ultimately, Arthritis Ireland has produced a suite of resources which will be referenced and used by patients, and will hopefully make a considerable impact on their quality of life.

Acknowledgments: This patient education programme was supported by a grant from UCB.

Disclosure of Interests: Brian Lynch Grant/research support from: Arthritis Ireland received a grant from MSD to develop this patient education programme. Brian Lynch has not benefited personally in any way.

DOI: 10.1136/annrheumdis-2020-eular.1214

\section{OP0309-PARE REUMASUTRA: RETHINKING SEXUALITY IN} RHEUMATIC AND MUSCULOSKELETAL DISEASES

J. B. Negrón ${ }^{1}$, L. Ponce ${ }^{2}$, L. R. G. Liga Reumatolóxica Galega ${ }^{3}$, L. R. C. Lliga Reumatològica Catalana ${ }^{4} .{ }^{1}$ Reumasutra LLC, Puerto Rico, United States of America; ${ }^{1}$ Reumasutra LLC, Puerto Rico, United States of America; ${ }^{3}$ Liga Reumatolóxica Galega Liga, A Coruña, Spain; ${ }^{4}$ Lliga Reumatològica Catalana, Barcelona, Spain

Background: Rheumatic and musculoskeletal diseases (RMDs) have a great impact on people's quality of life affecting daily tasks. Research has shown that sexual relationships are also affected by RMDs. This occurs by one or a combination of: (1) the symptoms of the disease and (2) the side effects of the medication. Although we are all here because of sex, talking about sex and sexuality remains taboo. Physicians themselves report that embarrassment, lack of time, lack of knowledge about the topic, or age are barriers that prevent them from starting a conversation about the subject. Consequently, the sexual sphere of people with RMDs is neglected; producing uncertainty in the people affected by them and their partners.

In 2016, we set ourselves the task of studying what has already been created. The only material we found was a book with drawings that showed several sexual positions. We realized that the existing material fell short and we knew that we could make an original contribution. That's why using participatory action research (PAR) approach we decided to create Reumasutra (LLC): The kamasutra for people with rheumatic diseases.

Objectives: To understand the complexities and the difficulties of sexuality in people with RMDs,

To offer a solution to the problems previously identified,

To (un)validate the proposed solution using the feedback of people with RMDs.

Methods: PAR affirms that experience can be a basis of knowing and that experiential learning can lead to a legitimate form of knowledge that influences practice.

PAR differs from conventional research in three ways. Firstly, it focuses on research whose purpose is to enable action. Secondly, PAR pays careful attention to power relationships, advocating for power to be deliberately shared between the researcher and the researched: blurring the line between them until the researched become the researchers. Thirdly, PAR contrasts with less dynamic approaches that remove data and information from their contexts, by advocating that those being researched should be involved in the process actively.

Results: Our project is divided into three phases.

In the first phase, interviews with people with RMDs were conducted. The interviewees expressed that sex remains a taboo topic, which is often ignored by physicians. Besides, we opened a suggestion box on the website www.reumaxxx com. Last year, we received feedback from approximately $>30.000$ people. After evaluating the feedback, it was clear that the best way to educate in sex in RMDs was by showing real people practicing adapted sexual positions.

For that task, we asked a couple with RMDs to validate the sexual positions that appear as drawings on the only book we found on the topic. Also, the couple added new sexual positions that they have been using and adapting to be sexually active despite having RMDs.

In the second phase, we recruited sex surrogates with experience with people with functional diversity to recreate the sexual position previously validated. The sex surrogates received coaching in real-time from a person with RMDs. The positions were filmed in January 2020.

For the last phase, we expect to upload the audiovisual content to the website. Afterward, we will send out surveys so that the users themselves can determine the validity and usefulness of the solution created.

Conclusion: Mobility in rheumatic diseases is affected. Sex is dynamic and a person cannot properly learn a new dynamic reality using static resources. We need to cross the taboo line to offer real solutions anchored to the reality of people with RMDs.

Acknowledgments: To Dr. Anne Campbell, John Campbell, Miss Estigia, Ivy de Luna, Sylvan, and Sally Fenaux and her crew.

Disclosure of Interests: None declared

DOI: 10.1136/annrheumdis-2020-eular.5246 